\title{
Isolation and Plant Growth Promoting Studies of Endophytic Fungi of Some Forest Plants
}

\author{
Femina Sobin* and Shalini Singh Deo
}

Department of Botany and Microbiology, St. Aloysius College (Autonomous), Jabalpur, India

*Corresponding author

\section{Keywords \\ Fungal endophytes, Forest plants, Plant growth promoting traits \\ Article Info \\ Accepted: \\ 17 June 2019 \\ Available Online: \\ 10 July 2019}

\section{A B S T R A C T}

The aims of the present work was to isolate and study fungal endophytes associated with eleven selected forest plants, collected from the district of Jabalpur, Madhya Pradesh. A total of 16 endophytic fungi were isolated from different tissue parts of these plants which were screened for their Plant growth promoting traits namely, IAA, ammonia, Urease production and phosphate solubilisation. Based upon their PGP traits four most potent endophytes were selected for further in vitro plant growth analysis including seed germination assay and effect of culture supernatant on the growth of Vigna sp. The findings of this study indicated that the isolated fungal endophyte identified as Fusarium sp. from Tectona grandis stem can play a crucial function to improve plant growth and could be utilized as biofertilizer or bioagent to establish a sustainable crop production

\section{Introduction}

The presence of non-pathogenic microbial cells inside the plants, other than the diseasecausing microorganisms, was first pronounced by De Bary (1866).

The term endophyte was derived from two Greek words, endo means within and phyte means plant. They include all microorganisms often bacteria or fungi that during a variable period of their life colonise the living internal tissues of their plant host (Pimentel et. al., 2011; Singh and Dubey, 2015).
Endophytes are known to enhance host growth and nutrient gain. They may improve the plant's abiotic and biotic stress tolerance ability and also enhance insect and pest resistance of plants. They are known to produce phytohormones and other bioactive compounds (Joseph and Priya, 2011).

This piece of work deals with the isolation of endophytes from selected forest trees of Jabalpur, Madhya Pradesh. Plant growth promoting activities of these isolates were analysed and some of these isolates may be promising candidate for the development of organic biofertilizer. 


\section{Materials and Methods}

\section{Sample collection}

Jabalpur is a district of Madhya Pradesh. The samples were collected from two areas of Jabalpur namely, State Forest Research Institute (SFRI), Bhim Nagar, Polipather and St. Aloysius' college (Autonomous), Sadar.

Forest plants selected for this study were Teak (sagon), Sal, Tendu, Mahua, Karanja, Khair, Bel, Shisham, Harra, Imli and Eucalyptus (Table 1).

Mature, healthy, asymptomatic forest plant material i.e. leaves and stems of these plants were removed with the help of sterilized scissors. Samples were stored in pre-sterilized zipper polythene bags with the help of sterile forceps. Samples from each plant were stored separately and details like date and place of collection, plant name were labelled on the polythene bags. It was then carried to the laboratory under aseptic condition and kept at $4^{\circ} \mathrm{C}$ until further use.

\section{Isolation of endophytic fungi}

The surface sterilization and isolation of fungal endophytes were carried out by the procedures described by Park et al., (2005).

Sterile samples were aseptically crumbled into small fragments, and evenly placed on Petri dishes containing PDA supplemented with $40 \mu \mathrm{g} / \mathrm{ml}$ streptomycin to inhibit the bacterial growth. The plates were incubated at $28^{\circ} \mathrm{C}$ until the outgrowth of endophytic fungi from the explants was observed. Small fragments of leaves and stems with fungal growth were removed with the aid of sterile forceps and placed on the prepared plates of potato dextrose agar and incubated at $28^{\circ} \mathrm{C}$ for 3-5days as described by Ripa et al., (2019). Subculturing was done after every six months.

\section{Screening of endophytes for plant growth promoting activities}

\section{Indole Acetic Acid (IAA) production assay}

Nutrient broth containing tryptophan $(1 \mathrm{mg} / \mathrm{ml})$ was prepared in culture tubes and inoculated with isolates followed by incubation at $27^{\circ} \mathrm{C}$ for $48 \mathrm{hrs}$ in a rotary orbital shaker incubator (SONAR) at 100rpm. A non-inoculated test tube was kept as negative control. Each $2 \mathrm{ml}$ of the supernatant from incubated tubes were mixed with $2 \mathrm{ml}$ of Salkowski's reagent. The presence of IAA was determined by the development of pink colour (Yasmin et al., 2004).

\section{Phosphate solubilization assay}

Fungal isolates were evaluated for the ability to solubilize inorganic phosphate in Pikovskaya's agar medium (HIMEDIA) containing calcium phosphate. Media containing sterile Petri plates were inoculated with isolated endophytes and incubated at $27^{\circ} \mathrm{C}$ for seven days. The presence of clear zone around the fungal colonies indicates the solubilisation of phosphate (Ripa et al., 2019).

\section{Ammonia production assay}

Fungal endophytes were tested for the production of ammonia in peptone water. Freshly grown fungal cultures were inoculated in $10 \mathrm{ml}$ peptone water in each tube separately and incubated for 48-72 hrs at $27^{\circ} \mathrm{C}$. Nessler's regent $(0.5 \mathrm{ml})$ was added in each tube. Development of brown to yellow colour indicates positive test for ammonia production (Cappuccino and Sherman, 1992).

\section{Urease production assay}

The ability of the isolates to attack nitrogen and carbon bonds in amide compounds was determined using Christensen's Urea broth containing $\mathrm{pH}$ indicator phenol red 
(Cappuccino and Sherman, 2002). A disc of fungal isolates were aseptically inoculated into above said broth and incubated at $27^{\circ} \mathrm{C}$ for 48hrs. Development of red colour indicates positive test i.e. urease was produced and yellow colour indicates negative test.

\section{In vivo plant growth promotion assay}

\section{Effect of culture supernatant on seed germination}

The ability of selected endophytic fungi to promote seedling growth was studied using cell-free supernatant according to Rajkumar and Freitas protocol (2008) with slight modification. Mung bean (Vigna sp.) seeds were used for the study. The seeds were surface-disinfected with sodium hypochlorite $(1.0 \% \mathrm{v} / \mathrm{v})$ for $10 \mathrm{~min}$ and washed with sterile distilled water. Equal numbers of seeds $(\sim 350)$ were incubated with $100 \mathrm{ml}$ of sterilized culture supernatant or distilled water, respectively, for $1 \mathrm{hr}$ at room temperature. One hundred seeds of each treatment were placed in sterile $0.8 \%$ agar plates and incubated at $27^{\circ} \mathrm{C}$ in the dark. All the treatments were made in triplicate. Visual assessments of seed germination were done daily up to 3 days. Every day, the number of seeds germinated was recorded and the average of germination was calculated for each treatment.

\section{Effect of culture supernatant on the growth of mung bean plants}

In order to evaluate the biofertilizer capacity of selected endophytic fungi on growth of Vigna sp., cell-free culture supernatant of selected endophyes were used to irrigate mung plants. Water and Fähraeus solution (supplemented with nitrogen, $0.5 \mathrm{~g} / \mathrm{L} \mathrm{NO}_{3} \mathrm{~K}$ ) were used as negative and positive control, respectively. Mung bean seeds were screened by shape, colour, and appearance in order to eliminate bad ones. They were surfacedisinfected with $70 \%$ ethanol for $5 \mathrm{~min}$ and washed (once) with sterile water. Finally, they were immersed in $1.0 \%$ sodium hypochlorite for $10 \mathrm{~min}$ followed by three washes with sterile water. Seeds were germinated for 4 days at $28^{\circ} \mathrm{C}$ in the dark on semisolid medium ( $0.5 \%$ agar). Then, germinated seeds were placed in pots with sterile soil as potting media. Four germinated seeds were sown at a suitable depth in all pots. During the experiment, each pot was irrigated with water, Fähraeus solution, culture supernatant 3 times over a period of 15 days. After day 15, all pots were irrigated with distilled water. Plants were then carefully removed from the pots and the root surface was cleaned several times with distilled water. Growth parameters such as fresh and dry weight of roots and shoots were recorded (Rajkumar and Freitas, 2008; Cavello et al., 2015).

\section{Identification of selected endophytic fungal isolate}

After this study the endophytic fungal isolate found to be potential plant growth promoter was identified by ITS sequencing and sequence was submitted to National Center for Biotechnology Information (NCBI).

\section{Results and Discussion}

\section{Sample collection}

A total of twenty two samples were collected from above mentioned forest plants (Table 2).

\section{Isolation of endophytic fungi}

Overall 16 endophytes were obtained from the samples collected, which were named as SA/L, IM/LB, IM/GS, IM/WS, TE/S, TE/L1, TE/L2, TE/L3, ML,MS, BE/L, BE/S, SH/L, EU/L, EU/S and KA/L. 
Screening of endophytes for plant growth promoting activities

In vitro studies of plant growth-promoting activities of the above mentioned fungal isolates were analyzed on four criterions namely -
a) Indole Acetic Acid(IAA) production ability
b) Phosphate solubilization ability
c) Ammonia production ability
d) Urease production ability

\section{Indole acetic acid (IAA) production assay}

In vitro testing of IAA production was done in nutrient broth supplemented with tryptophan and using Salkowski's reagent for IAA detection. Two strains were found to be positive, they are TE/S1 and TE/S2 as they developed pink colour.

Figure 1 displays test of all the endophytes for IAA production. Optical density of the positive samples was also measured. The optical density of positive samples TE/S1 and TE/S2 were recorded to be 2.187 and 2.561 respectively.

\section{Phosphate solubilization assay}

The ability to solubilize inorganic phosphate was qualitatively analysed in Pikovskaya's agar medium containing calcium phosphate. Only two isolates i.e. IM/LB and TE/L showed phosphate solubilization ability as they formed clear zone around the colonies of fungal endophytes. Figure 2 shows the positive samples. The diameter of positive samples were recorded to be $32.4 \mathrm{~mm}$ of $\mathrm{IM} / \mathrm{LB}$ and $12.1 \mathrm{~mm}$ of TE/L.

\section{Ammonia production assay}

Ammonia production was tested in peptone water. On addition of Nesseler's reagent two isolates developed brown to yellow colour indicating positive test. Figure 3 displays the positive samples i.e. TE/S and TE/S2.

\section{Urease production assay}

Urease production was determined using Christensen's urea broth containing $\mathrm{pH}$ indicator phenol red. Presence of red colour shows positive for urease and yellow as negative, the test performed is displayed in Figure 4 All the fungal isolates showed urease production positive.

Overall result of screening of isolated endophytes for their in vitro plant growth promoting activities showed that four of them were most potent of all isolates in its plant growth promoting activities. They were TE/S2, TE/S1, IM/LB and TE/L (Table 3).

\section{In vivo plant growth promotion assay}

Based on these plant growth promoting traits analysed the best four endophytes were selected for in vivo plant growth studies. Selected endophytes were TE/S2, TE/S1, $\mathrm{IM} / \mathrm{LB}$ and TE/L.

\section{Effect of culture supernatant on mung bean seed germination}

Seed Germination assay was carried out and seeds germinated each day were recorded up to three days which is displayed in Table 4. As experiment was performed in triplicates, average seeds germinated per day are displayed in this table.

On the third day average seed germination was calculated as 32.22 of TE/L, 38.88 of TE/S1, 42.66 of TE/S2, 43.11 of IM/LB and 27.33 of control. Among the four endophytes analysed for their seed germination enhancement effect, IM/LB culture supernatant was found to be the best (Graph 1) (Figure 4). 
Effect of culture supernatant on the growth of Mung bean plants

Growth promotion was studied using a 15 day plant growth assay, Fresh and dry weights and root and shoot length of the treated plants were recorded thereafter as shown in Table 5 (Figure 5).

After 15 days of plant growth promoting assay, average shoot length of seedlings were calculated as $18.4 \mathrm{~cm}$ of $\mathrm{TE} / \mathrm{S} 2,17.24 \mathrm{~cm}$ of $\mathrm{IM} / \mathrm{LB}, 7.75 \mathrm{~cm}$ of $\mathrm{TE} / \mathrm{S} 1$, and $3.9 \mathrm{~cm}$ of TE/L (Graph 2). TE/S2 culture supernatant has maximum effect on increasing shoot length.

Average root length of seedlings were calculated as $3.68 \mathrm{~cm}$ of TE/S2, $3.5 \mathrm{~cm}$ of
$\mathrm{IM} / \mathrm{LB}, 1.75 \mathrm{~cm}$ of TE/S1 and $1.5 \mathrm{~cm}$ of TE/L (Graph3). TE/S2 culture supernatant has maximum effect on increasing root length.

Average fresh weight of seedlings was calculated as $1.112 \mathrm{~g}$ of TE/S2, $1.102 \mathrm{~g}$ of $\mathrm{IM} / \mathrm{LB}, 1.049 \mathrm{~g}$ of TE/S1 and $0.49 \mathrm{~g}$ of TE/L (Graph 4). TE/S2 culture supernatant has maximum effect on increasing plant fresh weight.

Average dry weight of seedlings was calculated as $1.00 \mathrm{~g}$ of $\mathrm{TE} / \mathrm{S} 2,1.00 \mathrm{~g}$ of $\mathrm{IM} / \mathrm{LB}, 0.083 \mathrm{~g}$ of TE/S 1 and $0.031 \mathrm{~g}$ of TE/L (Graph 5). TE/S2 culture supernatant has maximum effect on increasing plant dry weight (Fig. 6).

Table.1 Forest plants selected for sample collection

\begin{tabular}{|c|c|c|c|}
\hline $\begin{array}{c}\text { Common } \\
\text { name }\end{array}$ & Botanical name & $\begin{array}{c}\text { Sample } \\
\text { part }\end{array}$ & Sampling site \\
\hline Teak/sagon & Tectonagrandis & \multirow{11}{*}{$\begin{array}{l}\text { Stem and } \\
\text { leaves }\end{array}$} & \multirow{9}{*}{$\begin{array}{l}\text { State Forest Research } \\
\text { Institute (SFRI), Bhim } \\
\text { Nagar, Polipather, Jabalpur, } \\
\text { Madhya Pradesh. }\end{array}$} \\
\hline Sal & Shorearobusta & & \\
\hline Tendu & Diospyros melonaxylon & & \\
\hline Mahua & Madhucaindica & & \\
\hline Khair & Acacia catechu & & \\
\hline Bel & Aegle marmelos & & \\
\hline Shisham & Dalbergialatifolia & & \\
\hline Harra & Terminalia chebula & & \\
\hline Karanja & Pongamiapinnata & & \\
\hline Imli & curcuma longa & & \multirow{2}{*}{$\begin{array}{l}\text { St. Aloysius' college } \\
\text { (Auto.), Jabalpur. }\end{array}$} \\
\hline Eucalyptus & Eucalyptus globulus & & \\
\hline
\end{tabular}

Table.2 Sample collection

\begin{tabular}{|l|c|}
\hline \multicolumn{1}{|c|}{ Sampling site } & No. of samples collected \\
\hline $\begin{array}{l}\text { State Forest Research Institute (SFRI), Bhim } \\
\text { Nagar, Polipathar, Jabalpur, Madhya Pradesh }\end{array}$ & 18 \\
\hline $\begin{array}{l}\text { St. Aloysius' College (Auto.), Jabalpur, Madhya } \\
\text { Pradesh }\end{array}$ & 4 \\
\hline
\end{tabular}


Table.3 In vitro screening of fungal isolates for its plant growth promoting activities

\begin{tabular}{|l|l|l|l|l|}
\hline Strain no. & $\begin{array}{c}\text { Indole acetic } \\
\text { acid (IAA) }\end{array}$ & $\begin{array}{c}\text { Phosphate } \\
\text { solubilization }\end{array}$ & $\begin{array}{c}\text { Ammonia } \\
\text { production }\end{array}$ & $\begin{array}{c}\text { Urease } \\
\text { production }\end{array}$ \\
\hline TE/S2 & Positive & negative & positive & Positive \\
\hline TE/S & Positive & negative & positive & Positive \\
\hline IM/LB & Negative & positive & negative & Positive \\
\hline TE/L & Negative & positive & negative & Positive \\
\hline
\end{tabular}

Table.4 Effect of culture supernatant on Mung bean germination

\begin{tabular}{|l|l|l|l|c|}
\hline Isolates & Day 1 & \multicolumn{1}{|c|}{ Day 2 } & Day 3 & $\begin{array}{c}\text { Average seed } \\
\text { germination } \\
\text { (Third day) }\end{array}$ \\
\hline \multicolumn{5}{|c|}{ Average of triplicates } \\
\hline TE/L & 34.66 & 38.66 & 23.33 & 32.22 \\
\hline TE/S1 & 40.66 & 35.33 & 40.66 & 38.88 \\
\hline TE/S2 & 42.66 & 46.33 & 39 & 42.66 \\
\hline IM/LB & 41 & 42.66 & 45.66 & 43.11 \\
\hline Control & 21 & 30 & 31 & 27.33 \\
\hline
\end{tabular}

Table.5 Record of length of roots and shoots along with their fresh and dry weight

\begin{tabular}{|l|l|l|l|l|}
\hline Strain No. & $\begin{array}{c}\text { Shoot } \\
\text { length } \\
\text { (cm) }\end{array}$ & $\begin{array}{c}\text { Root } \\
\text { length } \\
\text { (cm) }\end{array}$ & $\begin{array}{c}\text { Fresh } \\
\text { weight } \\
\text { (g) }\end{array}$ & $\begin{array}{c}\text { Dry } \\
\text { weight } \\
\text { (g) }\end{array}$ \\
\hline TE/S2 & 18.4 & 3.68 & 1.112 & 1.00 \\
\hline IM/LB & 17.24 & 3.5 & 1.102 & 1.00 \\
\hline TE/S1 & 7.75 & 1.75 & 1.049 & 0.083 \\
\hline TE/L & 3.9 & 1.5 & 0.49 & 0.031 \\
\hline Control & 13 & 3 & 1.00 & 0.090 \\
\hline
\end{tabular}

Graph.1 Seed germination assay
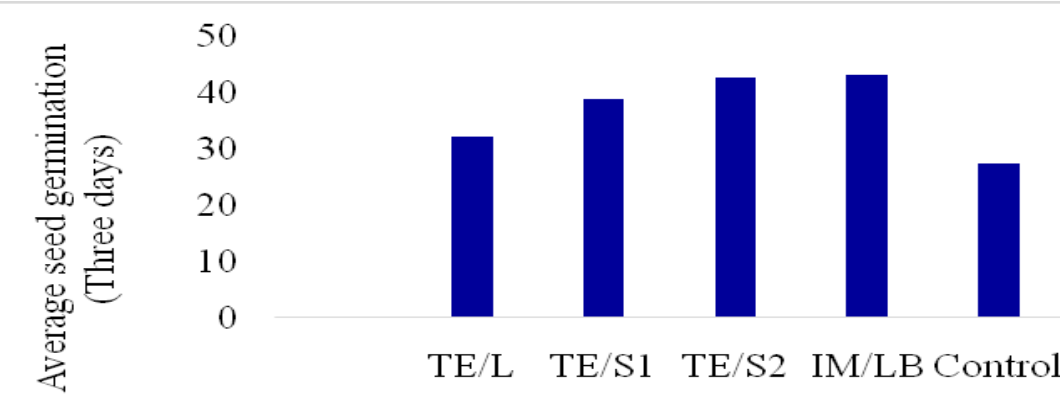

TE/L TE/S1 TE/S2 IM/LB Control Fungal Endophyte isolates 
Graph.2 Effect of selected culture supernatant on shoot length after pot experiment

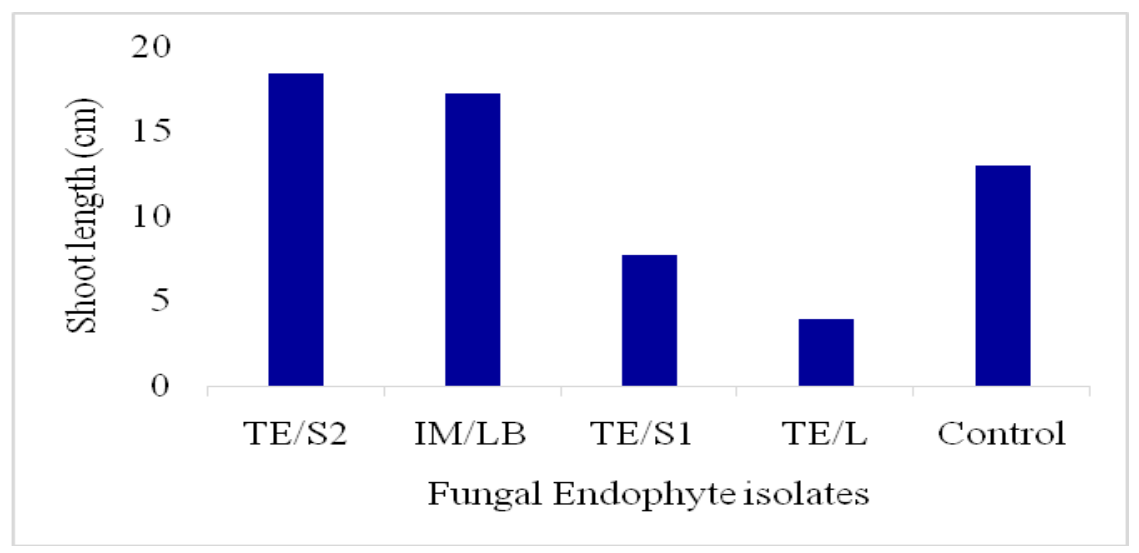

Graph.3 Effect of selected culture supernatant on root length after pot experiment

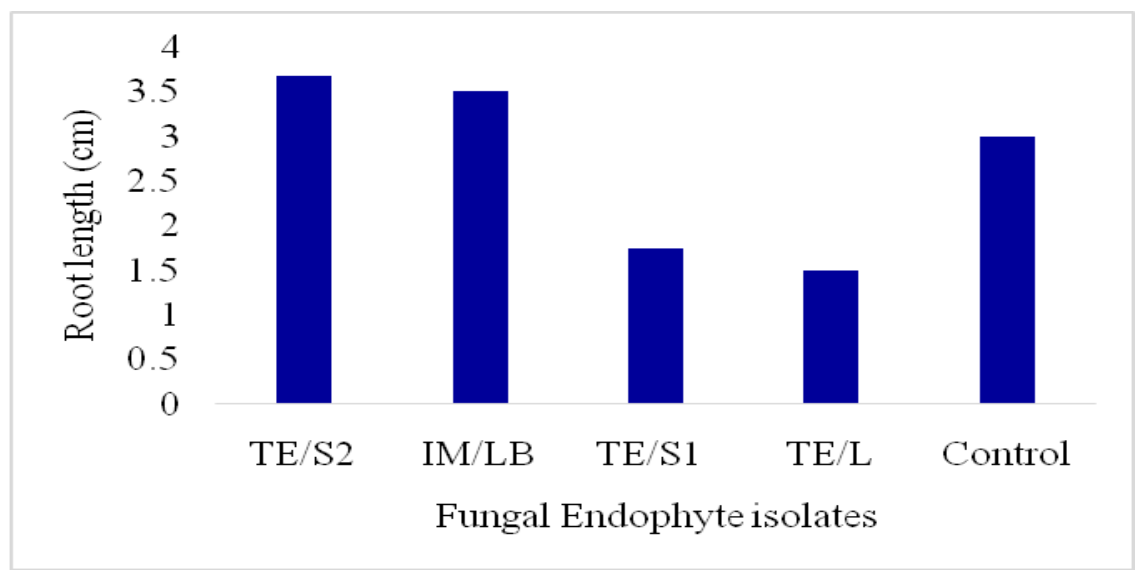

Graph.4 Effect of selected culture supernatant on fresh weight of plants after pot experiment

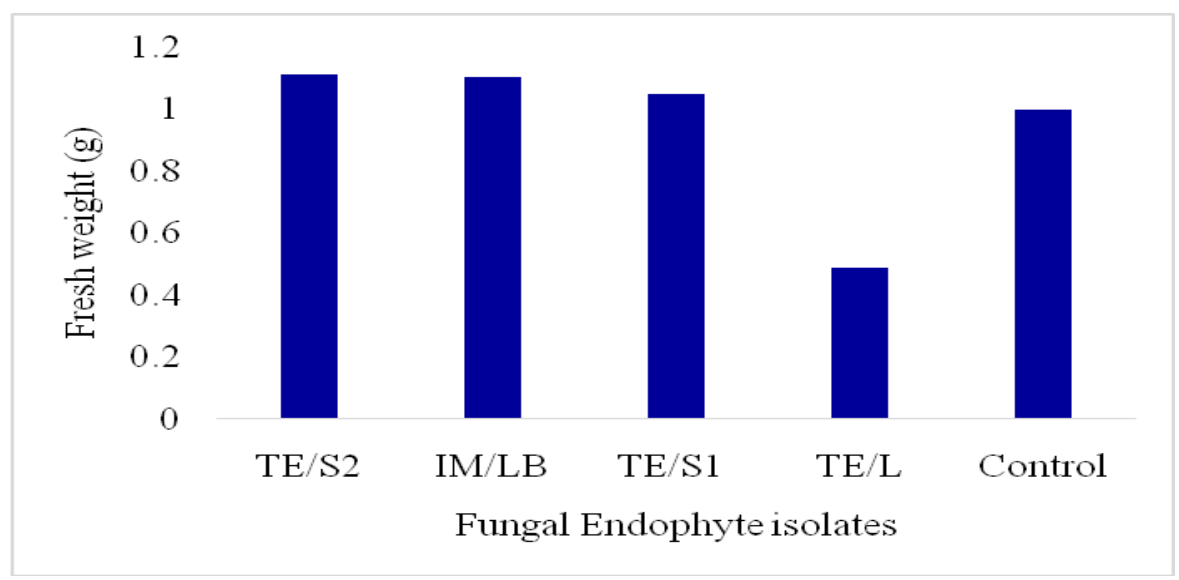


Graph.5 Effect of selected culture supernatant on dry weight of plants after pot experiment

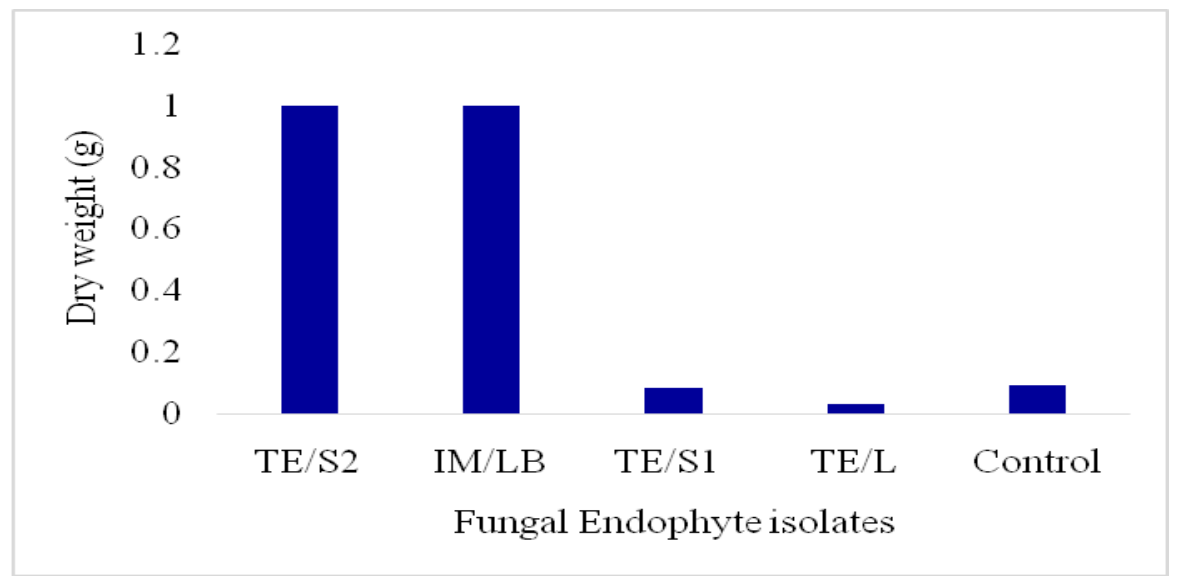

Figure.1(a) Indole acetic acid (IAA) production assay (b) TE/S and TE/S2 positive results with control respectively

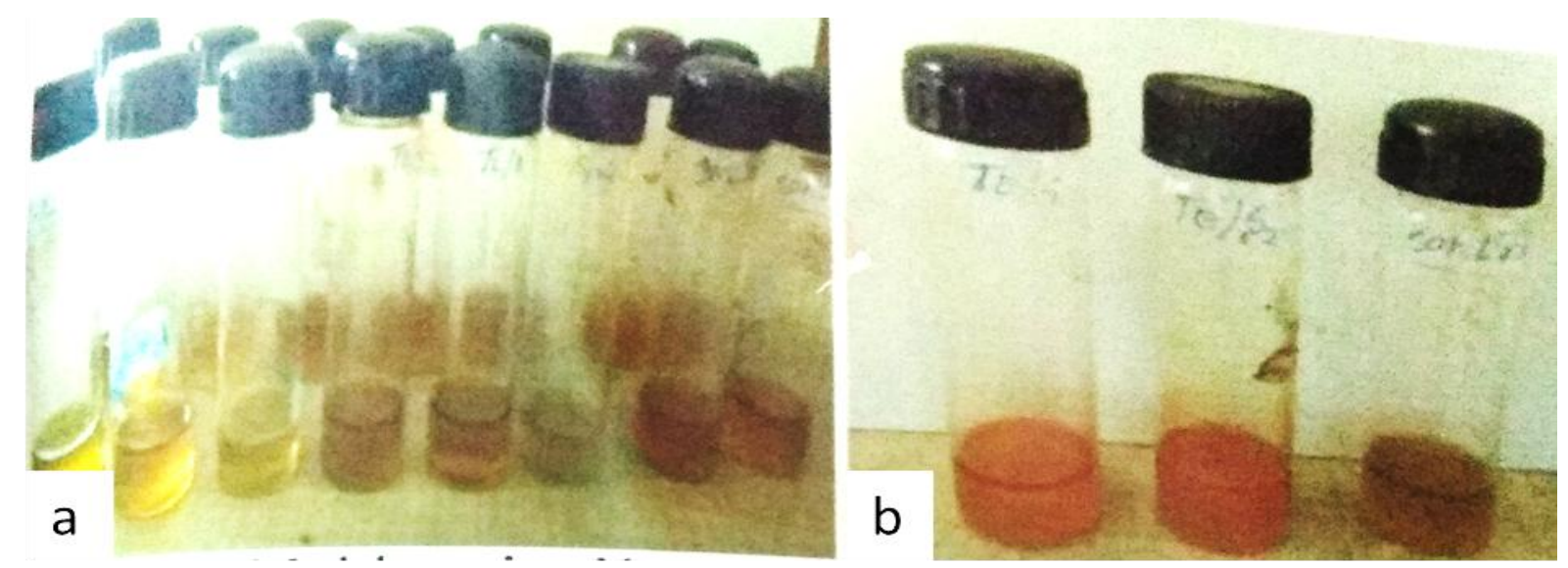

Figure.2 Positive results of Phosphate solubilization assay (a) TE/L (b) IM/LB
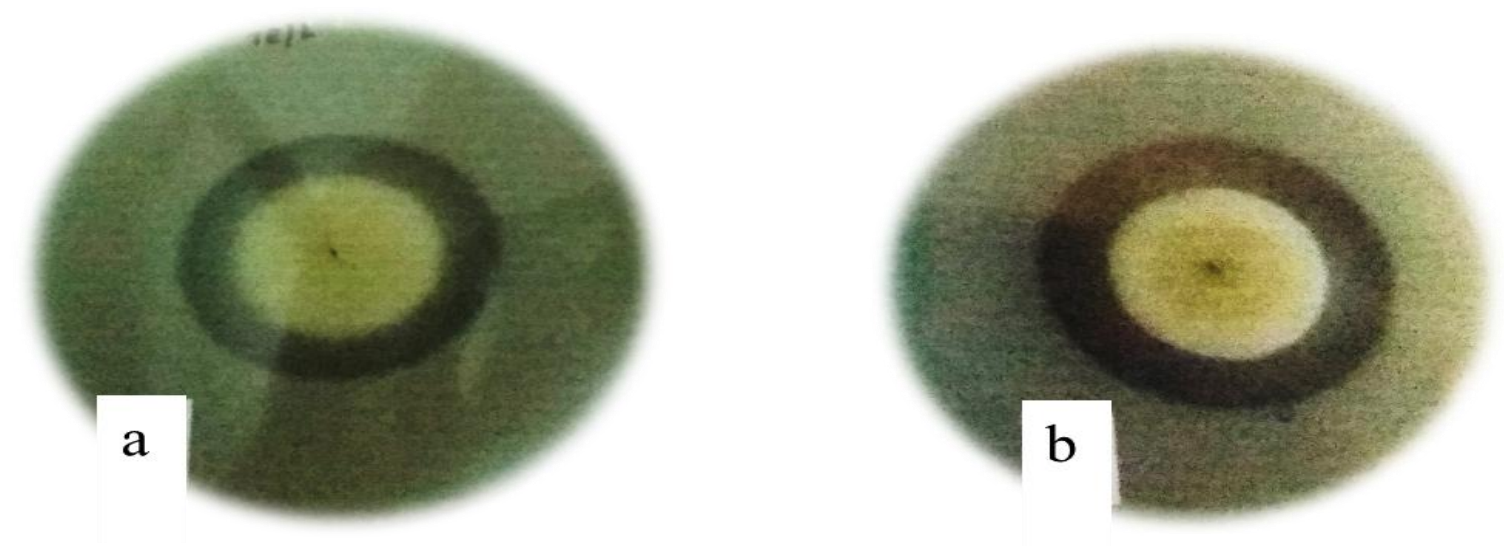

Figure.3 (a) Ammonia production assay (b) Control with positive samples TE/S2 and TE/S1 
respectively
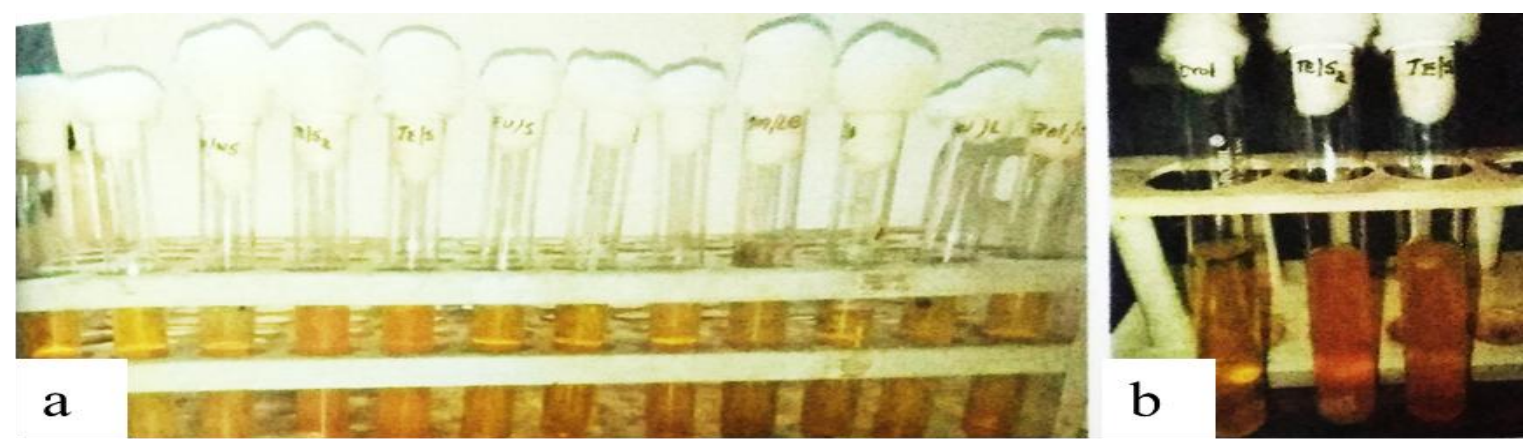

Figure.4 Urease production assay

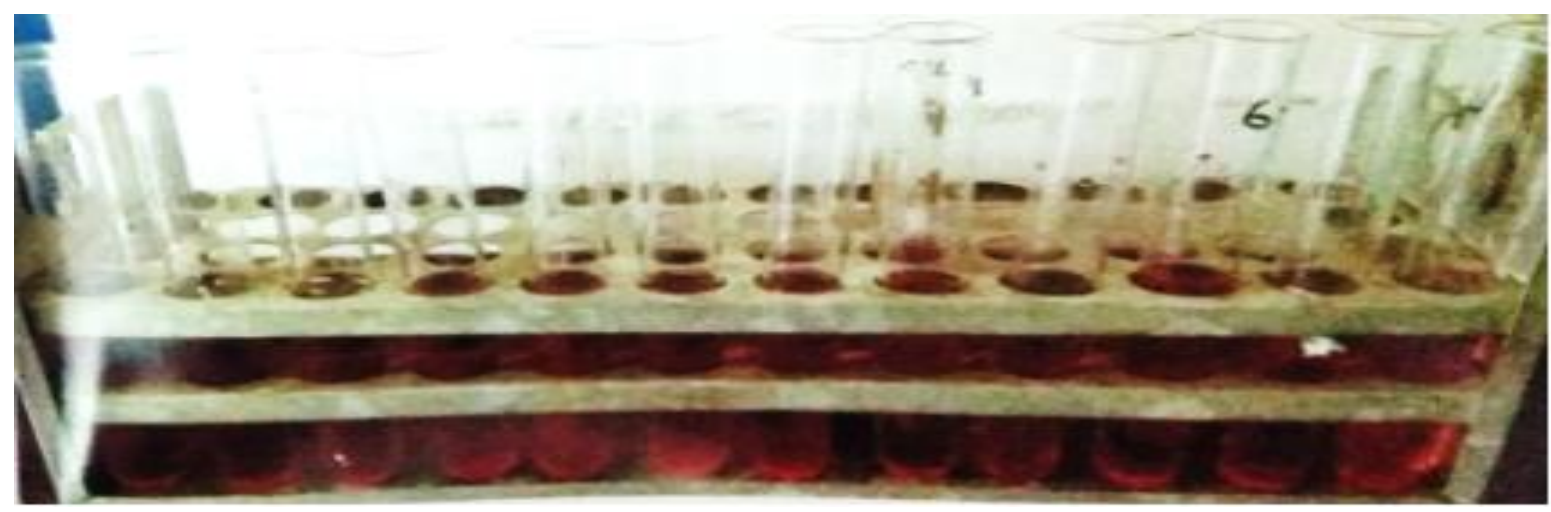

Figure.5 Seed germination assay on third day (a) TE/S2 (b) IM/LB (c) $\mathrm{TE} / \mathrm{S} 1$ (d) TE/L

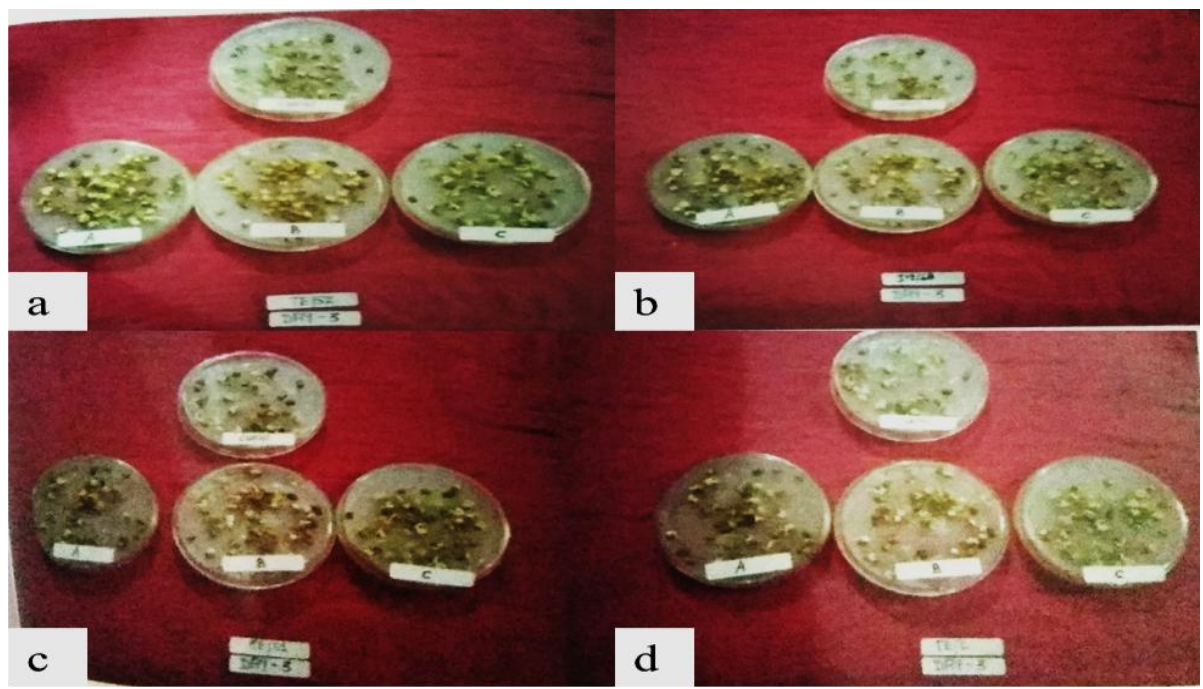

Figure.6 Mung plants treated with culture supernatant of (a) Control (b) TE/S1 (c) TE/L(d) IM/LB (e) TE/S2 


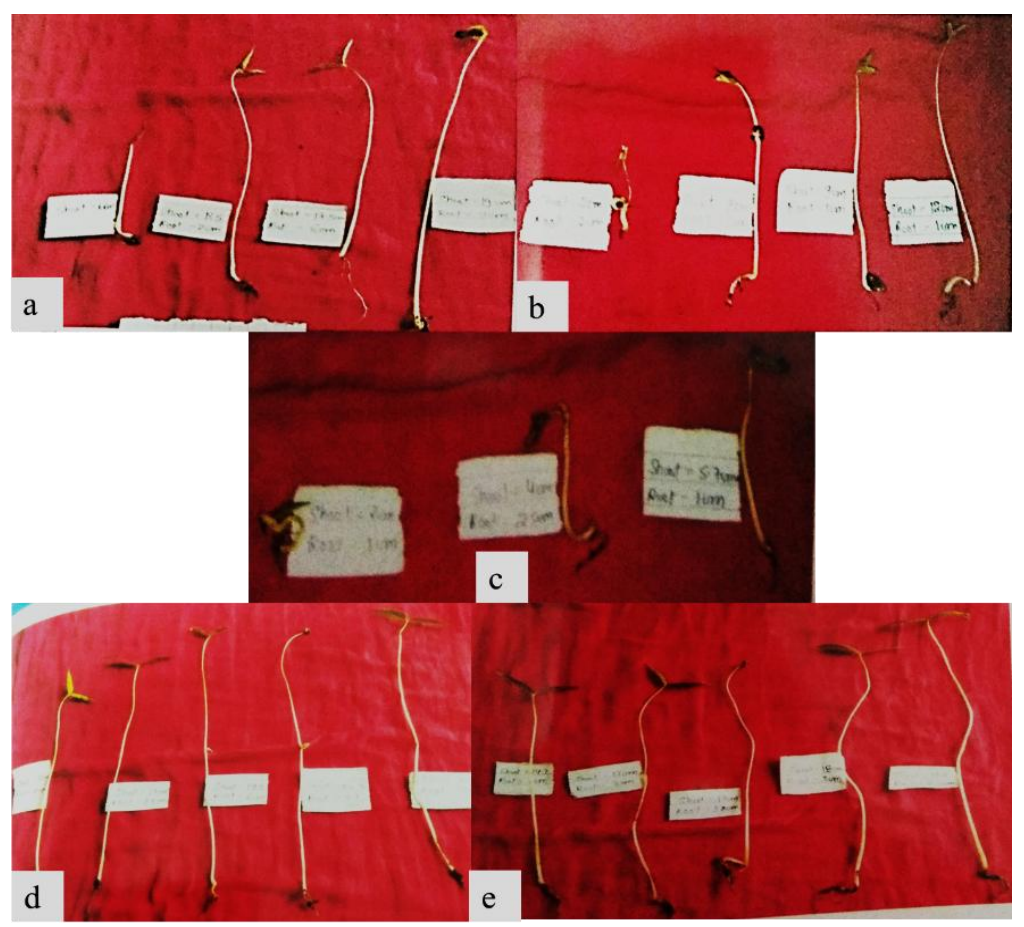

Identification of selected endophytic fungal isolate

After this study the Endophytic fungal isolate TE/S2 was found to be potential plant growth promoter it was identified as Fusarium sp. and GenBank accession number obtained by NCBI was SUB5027931 AMAY18364 Fusarium MK377167.

Cavello et al., (2015) showed in his studies that endophytic fungi possess plant growth promoting activity. Ripa et al., (2019) had disclosed that fungal endophytes isolated from wheat plants possess a crucial function to improve plant growth and could be utilized as biofertilizers or bioagents to establish a sustainable crop production system, they proved that endophytes exhibited fairly good indole acetic acid (IAA), phosphate solubilisation activities and ammonia production ability.

In conclusion, current trends in agriculture are focused on the reduction of the use of synthetic pesticides and inorganic fertilizers, forcing the search of alternative ways to improve a more sustainable agriculture. In this work, features dealing with plant growthpromoting activity were investigated. Functional traits such as IAA production, Phosphate solubilization, ammonia and urease production, may make this endophyte i.e. Fusarium sp. and its cell-free supernatant a potential source of biostimulant as well as biofertilizer.

\section{References}

Cappuccino J. C. and Sherman N. 1992. In: Microbiology: A Laboratory Manual, third ed. Benjamin/cummings Pub. Co. New York, pp. 125-179.

Cappuccino J. C. and Sherman N. 2002. In: Microbiology: A Laboratory Manual, (sixth ed.). Pearson

Cavello I. A., Crespo J. M., García S. S., Zapiola J. M., María F. Luna M. F. and Sebastián F. Cavalitto S. F. 2015. Plant Growth Promotion Activity of Keratinolytic Fungi Growing on a Recalcitrant Waste Known as (Hair Waste). Biotechnology Research International. 2015:1-10.

De Bary A. 1866. Morphologie und Physiologie der Pilze, Flechten und Myxomyceten Vol. 2. Leipzig: Hofmeister's Handbook of 
Physiological Botany.

Joseph B., Priya R. M. 2011. Bioactive compounds from endophytes and their potential in pharmaceutical effect: A review. Am. J. Biochem. Mol. Bio. 1: 291-309.

Park J. H., Choi G. J., Lee HB, Kim K. M., Jung H. S., Lee S. W. 2005. Griseofulvin from Xylaria sp. strain F0010, an endophytic fungus of Abies holophylla and its antifungal activity against plant pathogenic fungi. J. Microbiol. Biotechnol. 15: 112-117.

Pimentel M. R., Molina G., Dionisio A. P., Maróstica M. R., Pastore G. M. 2011. The Use of endophytes to obtain bioactive compounds and their application in biotransformation process. Biotechnol. Biotechnology Research International, 2011:1-11.

Rajkumar M. and Freitas H. 2008. Effects of inoculation of plant growth promoting bacteria on $\mathrm{Ni}$ uptake by Indian mustard. Bioresource Technology, vol. 99(9):34913498.

Ripa F. A., Cao W., Tong S. and Sum J. 2019. Assessment of plant growth promoting and abiotic stress tolerance properties of wheat endophytic fungi. BioMed Research International. 2019:1-12.

Singh R., Dubey A. K. 2015. Endophytic actinomycetes as emerging source for therapeutic compounds. Indo Global J. Pharm. Sci. 5 106-116.

Yasmin S., Baker M. A. R., Malik K. A. and Hafeez F. Y. 2004. Isolation, characterization and beneficial effects of rice-associated plant growth-promoting bacteria from Zanzibar soils. J. Basic Microbiol. 44(3):241-252.

\section{How to cite this article:}

Femina Sobin and Shalini Singh Deo. 2019. Isolation and Plant Growth Promoting Studies of Endophytic Fungi of Some Forest Plants. Int.J.Curr.Microbiol.App.Sci. 8(07): 2087-2097. doi: https://doi.org/10.20546/ijcmas.2019.807.251 